\title{
Sistem Pendukung Keputusan Penentuan Penerima Bantuan Siswa Miskin Metode Teorema Bayes
}

\author{
Anisyah Jatu Siti Nurjanah ${ }^{1)}$, Mutaqin Akbar ${ }^{2)}$ \\ ${ }^{1,2}$ Universitas Mercu Buana Yogyakarta \\ 1,2 Jl. Jembatan Merah 84 C Gejayan Yogyakarta \\ 1jatusiti4@gmail.com, ${ }^{2}$ mutaqin@mercubuana-yogya.ac.id
}

\begin{abstract}
Abstrak
Program Bantuan Siswa Miskin adalah Program Nasional yang bertujuan untuk menghilangkan halangan siswa miskin berpartisipasi untuk bersekolah dengan membantu siswa miskin memperoleh akses pelayanan pendidikan yang layak, mencegah putus sekolah, menarik siswa miskin untuk kembali bersekolah, membantu siswa memenuhi kebutuhan dalam kegiatan pembelajaran, mendukung program Wajib Belajar Pendidikan Dasar Sembilan Tahun (bahkan hingga tingkat menengah atas), serta membantu kelancaran program sekolah.

Pada penelitian ini digunakan metode Teorema Bayes. Teorema Bayes adalah teorema yang digunakan dalam statistika untuk menghitung peluang suatu hipotesis. Untuk variabel yang digunakan dalam penghitungan yakni 12 kriteria dan 2 golongan serta bobot-bobot kriteria terhadap masing-masing golongan.

Berdasarkan 50 data yang telah diujikan terhadap kepala sekolah dan sistem, sistem dapat mendeteksi 2 golongan yaitu rekomendasi dan non rekomendasi untuk siswa yang berhak dan tidaknya menerima bantuan siswa miskin dan sesuai dengan validasi kepala sekolah atau wakil kepala sekolah adalah 45 siswa dan yang tidak sesuai adalah 5 siswa. Berdasarkan hasil validasi kepala sekolah atau wakil kepala sekolah dan sistem, diperoleh akurasi $80 \%$ data kasus yang sesuai.
\end{abstract}

Kata kunci:Bantuan Siswa Miskin, Program Bantuan Siswa Miskin, Teorema Bayes

\section{PENDAHULUAN}

Program Bantuan Siswa Miskin adalah Program Nasional yang bertujuan untuk menghilangkan halangan siswa miskin berpartisipasi untuk bersekolah dengan membantu siswa miskin memperoleh akses pelayanan pendidikan yang layak, mencegah putus sekolah, menarik siswa miskin untuk kembali bersekolah, membantu siswa memenuhi kebutuhan dalam kegiatan pembelajaran, mendukung program Wajib Belajar Pendidikan Dasar Sembilan Tahun (bahkan hingga tingkat menengah atas), serta membantu kelancaran program sekolah. BSM adalah bantuan pemerintah berupa sejumlah uang tunai yang diberikan secara langsung kepada siswa yang berasal dari keluarga miskin.

Melalui Program BSM ini diharapkan anak usia sekolah dari rumah-tangga/keluarga miskin dapat terus bersekolah, tidak putus sekolah, dan di masa depan diharapkan mereka dapat memutus rantai kemiskinan yang saat ini dialami orangtuanya.
Program ini bersifat langsung kepada siswa dan bukan beasiswa karena berdasarkan kondisi ekonomi siswa dan bukan berdasarkan prestasi (beasiswa) mempertimbangkan kondisi siswa, sedangkan beasiswa diberikan dengan mempertimbangkan prestasi siswa.

Berdasarkan uraian diatas, maka peneliti dalam hal ini mengambil judul "Sistem Pendukung Keputusan Rekomendasi Bantuan Siswa Miskin Metode Teorema Bayes" menggunakan parameter-parameter tertentu yang nantinya dapat memberikan kemudahan bagi pengguna untuk mengetahui golongan yang sesuai.

\section{METODE PENELITIAN}

Untuk membangun sebuah sistem pendukung keputusan rekomendasi penerima bantuan siswa miskin menggunakan metode penelitian dapat dilihat pada Gambar 1 : 


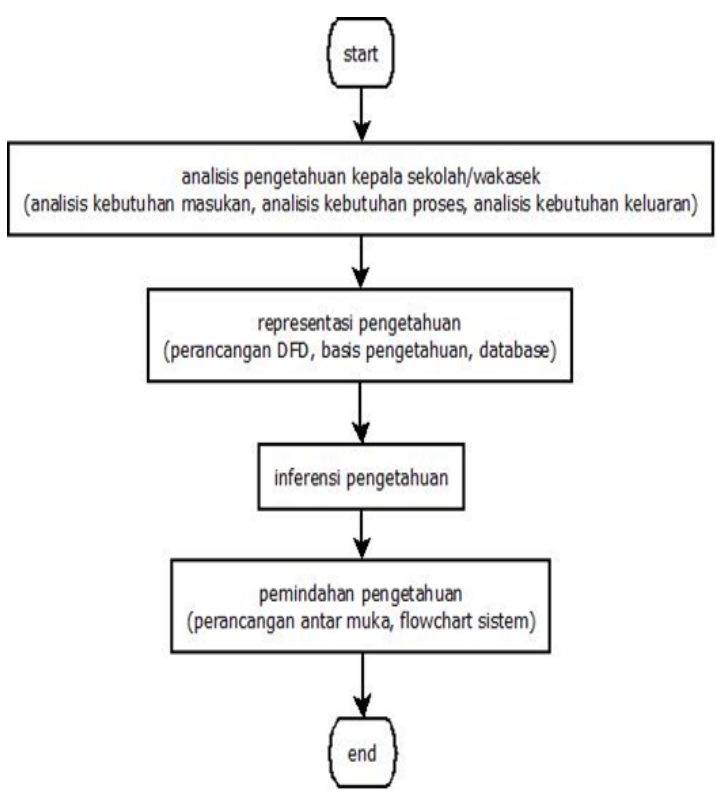

Gambar 1. Metode Penelitian

\section{a. Akuisisi Pengetahuan}

Akuisisi pengetahuan merupakan kegiatan untuk mencari dan megumpulkan data untuk analisis kebutuhan perangkat lunak yang bersumber dari seorang kepala sekolah / wakil kepala sekolah.

\section{b. Representasi Pengetahuan}

\section{1) Perancangan Use Case Diagram}

Use case diagram merupakan pemodelan untuk menggambarkan kelakuan (behavior) system yang akan dibuat. Use case diagram digunakan untuk mengetahui fungsi apa saja yang ada didalam sebuah sistem dan siapa saja yang berhak menggunakan fungsifungsi tersebut seperti pada Gambar 2 :

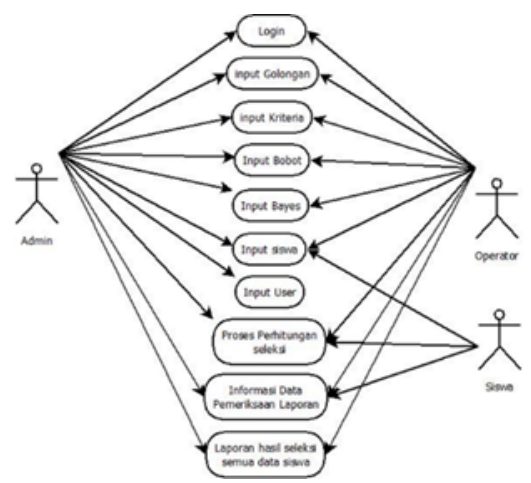

Gambar 2. Diagram Use Case

\section{2) Basis Pengetahuan}

Basis pengetahuan dirancang dengan beberapa data yaitu data golongan, data kriteria, data rule, dan bayes, data di atas dapat dilihat pada Tabel 2 sampai Tabel.
Tabel 1. Data Golongan

\begin{tabular}{|l|l|}
\hline $\begin{array}{l}\text { Kode } \\
\text { Golongan }\end{array}$ & Nama Golongan \\
\hline GOL01 & Recommended \\
\hline GOL02 & Non Recommended \\
\hline
\end{tabular}

Tabel 2. Data Rule

\begin{tabular}{|l|lr|}
\hline $\begin{array}{c}\text { Kode } \\
\text { Golongan }\end{array}$ & \multicolumn{2}{|c|}{ Aturan } \\
\hline GOL01 & $\begin{array}{l}\text { KT01, KT02, KT08, KT07, } \\
\text { KT09, KT10 dengan nilai } \\
\text { probabilitas 1 }\end{array}$ \\
\hline GOL02 & $\begin{array}{l}\text { KT03, KT04, KT05, KT06, } \\
\text { KT11, KT12 dengan nilai } \\
\text { probabilitas 1 }\end{array}$ \\
\hline
\end{tabular}

Table 3. Data Kriteria

\begin{tabular}{|l|l|}
\hline $\begin{array}{c}\text { Kode } \\
\text { Kriteria }\end{array}$ & \multicolumn{1}{|c|}{ Nama Kriteria } \\
\hline KT01 & 500.000 (Gaji Orang Tua) \\
\hline KT02 & $\begin{array}{l}600.000-1.500 .000 \text { (Gaji Orang } \\
\text { Tua) }\end{array}$ \\
\hline KT03 & $\begin{array}{l}1.600 .000-2.900 .000 \text { (Gaji Orang } \\
\text { Tua) }\end{array}$ \\
\hline KT04 & 3000.000 (Gaji Orang Tua) \\
\hline KT05 & Kurang (Presensi) \\
\hline KT06 & Cukup (Presensi) \\
\hline KT07 & Baik (Presensi) \\
\hline KT08 & Sangat Baik (Presensi) \\
\hline KT09 & Buruh (Profesi Orang Tua) \\
\hline KT10 & $\begin{array}{l}\text { Pengangguran (Profesi Orang } \\
\text { Tua) }\end{array}$ \\
\hline KT11 & Wiraswasta ( Profesi Orang Tua) \\
\hline KT12 & PNS (Profesi Orang Tua) \\
\hline KT13 & KIP \\
\hline KT14 & NON KIP \\
\hline
\end{tabular}

Table 4. Bayes

\begin{tabular}{|l|l|l|}
\hline No & \multicolumn{1}{|c|}{$\begin{array}{c}\text { Nilai } \\
\text { Bayes }\end{array}$} & \multicolumn{1}{|c|}{ Teorema Bayes } \\
\hline $\mathbf{1}$ & $0-0.2$ & Tidak ada \\
\hline $\mathbf{2}$ & $0.3-0.4$ & Mungkin \\
\hline $\mathbf{3}$ & $0.5-0.6$ & Kemungkinan Besar \\
\hline $\mathbf{4}$ & $0.7-0.8$ & Hampir Pasti \\
\hline $\mathbf{5}$ & $0.9-1$ & Pasti \\
\hline
\end{tabular}




\section{3) Perancangan Database}

Perancangan database dapat dilihat pada Gambar 3 :

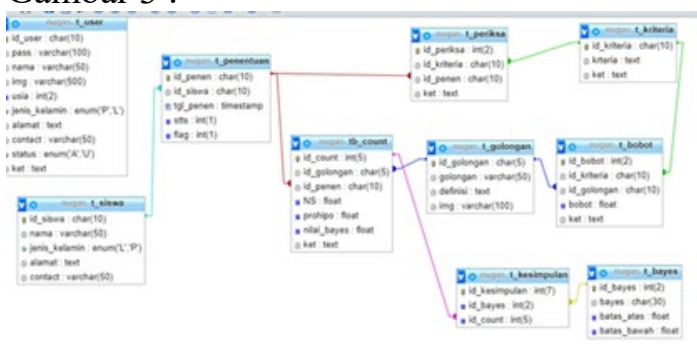

Gambar 3 Database

\section{4) Flowchart Sistem}

Gambar 4

Flowchart sistem dapat dilihat pada

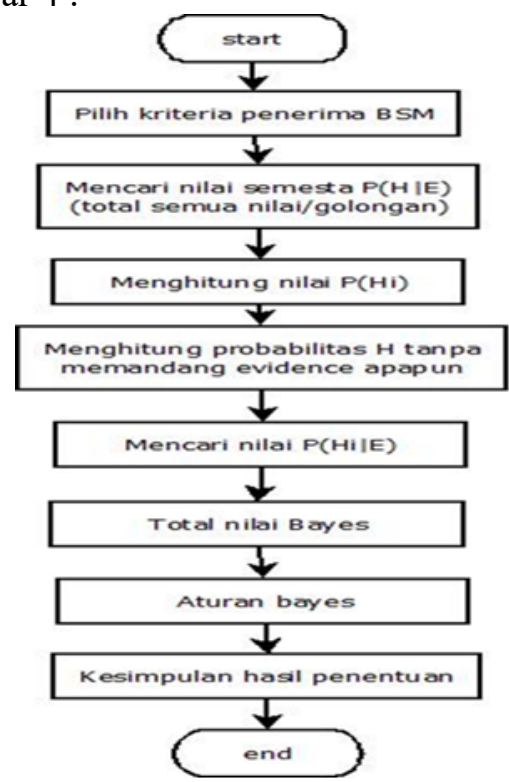

Gambar 4. Flowchart Sistem

\section{TINJAUAN PUSTAKA}

a. Bantuan Siswa Miskin (BSM)

Program BSM merupakan program yang diluncurkan oleh pemerintah untuk menanggulangi masalah putus sekolah pada usia dini, program BSM juga dimaksudkan agar siswa miskin yang telah tamat dapat melanjutkan pendidikannya ke jenjang lebih tinggi dengan pendidikan yang layak (Ramadhan, 2014).

\section{b. Sistem Pendukung Keputusan}

Sistem Pendukung Keputusan (SPK) adalah bagian dari sistem informasi berbasis komputer termasuk sistem berbasis pengetahuan atau manajemen pengetahuan yang dipakai untuk mendukung pengambilan keputusan dalam suatu organisasi atau perusahaan. Dapat juga dikatakan sebagai sistem komputer yang mengolah data menjadi informasi untuk mengambil keputusan dari masalah semi terstruktur yang spesifik (Purba, 2015).

\section{c. Teorema Bayes}

Teorema Bayes adalah teorema yang digunakan dalam statistika untuk menghitung peluang untuk suatu hipotesis. Bayes Optimal Classifier menghitung peluang dari suatu kelas dari masing-masing kelompok atribut yang ada, dan menentukan kelas mana yang paling optimal (Hulaifah, Nasution, \& Anra, 2016).

Dalam penelitian ini menggunakan Metode Bayes. Langkah - langkah penyelesaiannya adalah (Dahri, Agus, \& Khairina, 2016) :

1) Menentukan kriteria-kriteria yang akan dijadikan acuan dalam pengambilan keputusan, yaitu Ci.

2) Menentukan hasil dari matriks bobot probabilitas.

3) Mencari nilai dari hasil evidence dari nilai alternatif berdasarkan probabilitas dterima dan ditolak.

4) Mengkalikan nilai evidence (E) dan selisih evidence (1-E).

5) Langkah penyelesaian teorema bayes.

Dalam teorema bayes langkah awal dari perhitungan yag dilakukan adalah mencari nilai semesta hipotesa $(\mathrm{H})$ yang terdapat pada evidence kemudian dijumlahkan semua nilai probabilitas evidence dari kepala sekolah. Untuk langkah - langkah lebih jelasnya sebagai berikut :

1) Mencari nilai semesta

$\sum_{\text {Kriteria }}^{\text {Golongan }}=G J 01+G J 02+G J 03+\cdots n$..(1)

2) Menghitung nilai semesta $P(\mathrm{Hi})$

$\mathrm{P}(\mathrm{H} 1,2, \ldots n)=\frac{H 1,2, \ldots n}{\sum_{k=1}^{p 01}}$

3) Menghitung Probabilitas $\mathrm{H}$

$\sum_{G 01}^{P 01}=P(H i) \times P(E \mid H i-n)$

4) Mencari nilai $\mathrm{P}(\mathrm{Hi} \mid \mathrm{E})$

$P(H i \mid E)=\frac{P(E \mid H) \times P(H i)}{P(H)}$.

5) Menghitung total nilai bayes

$\sum_{k=2}^{P 02}$ Bayes $=$ Bayes $1+$ Bayes $2+\cdots n(5)$

\section{d. Forward Chaining}

Forward chaining merupakan grup dari multiple inferensi yang melakukan pencarian dari suatu masalah kepada solusinya. Forward chaining adalah data-driven karena inferensi 
dimulai dengan informasi yang tersedia dan baru konklusi diperoleh (Hanggowibowo, 2009). Berikut contoh cara kerja Forward Chaining :

Tabel 5. Tabel Forward Chaining

\begin{tabular}{|l|l|l|}
\hline Data & Aturan & Kesimpulan \\
\hline $\mathrm{A}=$ & Jika $\mathrm{A}=$ & $\mathrm{A}=$ \\
Rekomen & Rekomendasi & Rekomendas \\
dasi & maka sebagai & $\mathrm{i} \quad$ berhak \\
& penerima & menerima \\
& Bantuan Siswa & Bantuan \\
& Miskin (BSM) & Siswa \\
& & Miskin. \\
\hline
\end{tabular}

\section{HASIL DAN PEMBAHASAN}

Dalam Perancangan sistem pendukung keputusan ini menggunakan metode teorema bayes dan forward chaining. Teorema bayes dimulai dari mencari nilai semesta total bobot kriteria dari tiap golongan lalu menghitung nilai semesta $\mathrm{P}(\mathrm{Hi})$ di lanjutkan dengan menghitung probalitas $(\mathrm{H})$ tanpa memandang evidence apapun barulah mencari nilai $\mathrm{P}$ (Hi E) dan langkah terakhir menjumlahkan nilai bayes.

Dalam proses perhitungan teorema bayes pada sistem pendukung keputusan rekomendasi penerima bantuan siswa miskin adalah sebagai berikut :

Tabel 6 Sampel data

\begin{tabular}{|l|l|l|l|}
\hline No & Nama Siswa & $\begin{array}{l}\text { Jenis } \\
\text { Kelamin }\end{array}$ & Kriteria \\
\hline 1 & $\begin{array}{l}\text { Angga } \\
\text { Kurniawan }\end{array}$ & L & $\begin{array}{l}\text { K3, K6, } \\
\text { K9, K13 }\end{array}$ \\
\hline
\end{tabular}

Keterangan :

Langkah - langkah perhitungannya sebagai berikut :

a. Step 1 Permasalahan

Diketahui daftar golongan pada Tabel 6.

- Rule sistem

- Rule kriteria terpilih adalah :

$>$ KT3, KT6, KT9, KT13 pada Rule GOL01

- Rule Sistem

> Rule GOL01 adalah KT03, KT06, KT09, KT13 dengan nilai probabilitas 1 .

- Dimana

$>\mathrm{KT} 01=\mathrm{P} . \mathrm{BAIK}$

$>\mathrm{KT} 06=\mathrm{G} .600 .000 \mathrm{~s} / \mathrm{d} 1.500 .000$

$>\mathrm{KT} 09=$ PRO.BURUH

$>\mathrm{KT} 13=$ PUNYA KIP.

b. Step 3 nilai probabilitas kepala sekolah kriteria terhadap golongan.
Nilai probabilitas yang diberikan kepala sekolah untuk masing-masing kriteria terhadap golongan.

- Nilai probabilitas kriteria pada GOL01.

$>\mathrm{KT} 03=0.7$.

$>\mathrm{KT} 04=0.9$.

$>\mathrm{KT} 05=0.9$.

KT06 $=0.7$.

$>\mathrm{KT} 09=0.9$.

$>\mathrm{KT} 10=0.6$

$>\mathrm{KT} 13=0.8$

- Nilai probabilitas gejala pada GOL02.

$>\mathrm{KT} 01=0.8$.

$>\mathrm{KT} 02=0.6$.

$>\mathrm{KT} 07=0.6$

$>\mathrm{KT} 08=0.9$.

$>\mathrm{KT} 11=0.9$.

$>\mathrm{KT} 12=0.7$.

$>\mathrm{KT} 14=0.9$.

Langkah perhitungan adalah sebagai berikut :

- KT03, KT06, KT09, KT13 pada rule GOL01.

- Mencari nilai semesta

Nilai Semesta $=0.7+0.7+0.8+0.9=3.1$

- Menghitung nilai semesta $\mathrm{P}(\mathrm{Hi})$

$>\mathrm{P}(\mathrm{H} 1)=0.7 / 3.1=0.225$

$>\mathrm{P}(\mathrm{H} 2)=0.7 / 3.1=0.225$

$>\mathrm{P}(\mathrm{H} 3)=0.8 / 3.1=0.258$

$>\mathrm{P}(\mathrm{H} 4)=0.9 / 3.1=0.290$

- Menghitung probabilitas H tanpa memandang evidence apapun

$>\mathrm{P}(\mathrm{H} 1) * \mathrm{P}(\mathrm{E} \mid \mathrm{H} 1)=0.225 * 0.7=0.157$

$>\mathrm{P}(\mathrm{H} 2) * \mathrm{P}(\mathrm{E} \mid \mathrm{H} 2)=0.225 * 0.7=0.157$

$>\mathrm{P}(\mathrm{H} 3) * \mathrm{P}(\mathrm{E} \mid \mathrm{H} 3)=0.258 * 0.8=0.206$

$\mathrm{P}(\mathrm{H} 4) * \mathrm{P}(\mathrm{E} \mid \mathrm{H} 4)=0.290 * 0.9=0.261$

Total Hipotesa $(\mathbf{H})=\mathbf{0 . 7 8 1}$

- Mencari nilai $\mathrm{P}(\mathrm{Hi} \mid \mathrm{E})$

$>\mathrm{P}(\mathrm{H} 1 \mid \mathrm{E})=(\mathrm{P}(\mathrm{H} 1) * \mathrm{P}(\mathrm{E} \mid \mathrm{H} 1)) / \mathrm{H}=$ $(0.225 * 0.7) / 0.781=0.201$

$>\mathrm{P}(\mathrm{H} 2 \mid \mathrm{E})=(\mathrm{P}(\mathrm{H} 1) * \mathrm{P}(\mathrm{E} \mid \mathrm{H} 1)) / \mathrm{H}=$ $(0.225 * 0.7) / 0.781=0.201$

> $\mathrm{P}(\mathrm{H} 3 \mid \mathrm{E})=(\mathrm{P}(\mathrm{H} 1) * \mathrm{P}(\mathrm{E} \mid \mathrm{H} 1)) / \mathrm{H}=$ $(0.258 * 0.8) / 0.781=0.264$

$\mathrm{P}(\mathrm{H} 4 \mid \mathrm{E})=(\mathrm{P}(\mathrm{H} 1) * \mathrm{P}(\mathrm{E} \mid \mathrm{H} 1)) / \mathrm{H}=$ $(0.290 * 0.9) / 0.781=0.334$

- Menghitung total nilai bayes

Nilai Bayes $=(0.7 * 0.201)+(0.7 * 0.201)$

$+(0.8 * 0.264)+(0.9 * 0.334)=0.7932$

Pada KT03, KT06, KT09, KT13 pada rule GOL01 diperoleh nilai 0.7932, jika dicocokkan dengan Tabel aturan bayes maka hasilnya 0.7-0.9 yang artinya "Hampir Pasti". 
Dari hasil perhitungan data sampel pengujian diatas didapat bahwa rekomendasi kemungkinan penerima bantuan siswa miskin dengan nama Angga Kurniawan dapat dilihat pada Tabel 7.

\begin{tabular}{|l|l|l|l|}
\hline $\begin{array}{l}\text { Nama } \\
\text { Siswa }\end{array}$ & $\begin{array}{l}\text { Hasil } \\
\text { Golongan }\end{array}$ & $\begin{array}{l}\text { Hasil } \\
\text { Hitun } \\
\mathrm{g}\end{array}$ & $\begin{array}{l}\text { Aturan } \\
\text { Inferen } \\
\text { si }\end{array}$ \\
\hline $\begin{array}{l}\text { Angga } \\
\text { Kurniawa } \\
\mathrm{n}\end{array}$ & $\begin{array}{l}\text { Recommendas } \\
\mathrm{i}\end{array}$ & 0.7932 & $\begin{array}{l}\text { Hampi } \\
\text { r Pasti }\end{array}$ \\
\hline
\end{tabular}

Dari Tabel 7 hasil hitung diambil nilai paling tinggi dari setiap kriteria terpilih yang dihitung berdasarkan golongan yang ada, didapatkan bahwa golongan "Rekomendasi" mendapat nilai paling tinggi yaitu 0.7932, selanjutnya dicocokan dengan Tabel aturan bayes yaitu nilai 0.7-0.8 adalah "Hampir pasti". Maka siswa dengan nama DFR01 ditentukan sebagai golongan "Rekomendasi".

\section{KESIMPULAN DAN SARAN \\ a. Kesimpulan}

Dari penelitian yang dilakukan, kesimpulan yaitu sistem yang dirancang dengan implementasi metode teorema bayes dapat digunakan untuk membantu dalam rekomendasi penerima bantuan siswa miskin, hasil implementasi dapat berjalan sesuai dengan desain, berdasarkan 50 data yang telah diujikan terhadap kepala sekolah dan sistem, untuk siswa yang sebagai golongan penerima bantuan siswa miskin dan sesuai dengan validasi kepala sekolah adalah 45 siswa dan yang tidak sesuai adalah 5 siswa. Sehingga untuk tingkat akurasi sistem berdasarkan hasil validasi kepala sekolah atau wakil kepala sekolah dan sistem, diperoleh presentase $80 \%$ data kasus yang sesuai, serta $20 \%$ data kasus yang tidak sesuai.

\section{b. Saran}

Sebagai saran penelitian selanjutnya, dalam penentuan data siswa sebaiknya menggunakan lebih banyak data lagi dan dengan menggabungkan atau dikonversi dengan metode lain agar mendapat hasil penentuan yang lebih obyektif.

\section{REFERENSI}

Amborowati, A., \& Hidayah , N. (2016). Analisis an Perancangan Sistem Pakar Diagnosa Penyakit Mematikan pada Perempuan Menggunakan Metode
Bayes (studi kasus : Asri Medical Center). Seminar Nasional Teknologi Informasi dan Multimedia 2016, 1.

Anggara, G., Pramayu, G., \& Wicaksana, A. (2016). Membangun Sistem Pakar Menggunakan Teorema Bayes untuk Mendiagnosa Penyakit Paru-paru. Seminar Nasional Teknologi Informasi dan Multimedia 2016, 1.

Assrani, D., Huda, N., Sidabutar, R., Saputra, I., \& Sulaiman, O. K. (2018). Penentuan Penerima Bantuan Siswa Miskin Menerapkan Metode Multi Objective Optimization on The Basis of Ratio Analysis (MOORA). JURNAL RISET KOMPUTER (JURIKOM), Vol. 5 No. 1, 1-5.

Dyan dkk. (2018). Klasifikasi Penyakit Kulit Pada Manusia Menggunakan Metode Binary. Jurnal Pengembangan Teknologi Informasi dan Ilmu Komputer, 2, 1912-1920. Retrieved Juli 17, 2018

Mahendra, V. G. (2016). SISTEM PENDUKUNG KEPUTUSAN BANTUAN SISWA MISKIN (BSM) DI SDN 3 PONCOKRESNO MENGGUNAKAN METODE SIMPLE ADDITIVE WEIGHTING (SAW). KONFERENSI MAHASISWA SISTEM INFORMASI, Vol 4, No 1 (2016), 256-261.

Mufizar, T., Nuraen, T., \& Andrianto, D. (2015). SISTEM PENDUKUNG KEPUTUSAN UNTUK MENYELEKSI CALON PENERIMA BANTUAN SISWA MISKIN (BSM) DI MTs NEGERI CIAMIS MENGGUNAKAN METODE SIMPLE ADDITIVE WEIGHTING (SAW). Seminar Nasional Informatika 2015, 671 677.

Sudarsono, N., Nuraen, T., \& Rahmawati, S. (2016). SISTEM PENUNJANG KEPUTUSAN PEMBERIAN BANTUAN SISWA MISKIN DI SD NEGERI SUKAMENAK KOTA TASIKMALAYA MENGGUNAKAN METODE TECHNIQUE FOR ORDER PREFERENCE BY SIMILARITY TO IDEAL SOLUTION (TOPSIS). Seminar Nasional Teknologi 
Jurnal INFORMA Politeknik Indonusa Surakarta p-ISSN : 2442-7942, e-ISSN 2716-5051

Vol. 6 Nomor 2 Desember 2020

Informasi dan Multimedia 2016, 163 168.

Sugeng. (2016). Pengertian, Bagian-Bagian, dan Fungsi Kulit Menurut Para Ahli Biologi Beserta 20 Penyakit Kulit. Retrieved Oktober 27, 2017, from Seputarilmu.com.

Surya, C. (2015). Sistem Pendukung Keputusan Rekomendasi Penerima Beasiswa Menggunakan Fuzzy Multi Attribut Decision Making (FMADM) dan Simple Additive Weighting (SAW). Jurnal Rekayasa Elektrika, Vol. 11, No. 4, 149 - 156. 